\title{
Use of carbon dioxide for therapeutic decision-making in endoleaks: a case report
}

\author{
Uso de $\mathrm{CO}_{2}$ na tomada de decisão terapêutica de endoleak: relato de caso \\ Adalberto Batalha Megale ${ }^{1}$ (D), Cynthia de Almeida Mendes ${ }^{1}$, Marcelo Passos Teivelis ${ }^{1}$, Carolina Brito Faustino ${ }^{1}$, \\ Kauê Polizel Souza', Nelson Wolosker ${ }^{1}$
}

\begin{abstract}
Endovascular aneurysm repair is currently the most frequently treatment modality for infrarenal aortic aneurysms. Endoleaks are the most common cause of reintervention after endovascular aneurysm repair. It is often unclear which type of endoleak is the correct diagnose, making the treatment decision difficult. We report the case of a 72-year-old man with an endoleak two years after endovascular aneurysm repair. Images suggested a type III endoleak, but this was not confirmed by contrast aortography. We proceeded with the investigation using aortography with carbon dioxide and observed a type IA endoleak. This was successfully treated by implantation of a proximal cuff. A review of the literature shows that the role of carbon dioxide in endoleak management is still unclear. We present a case in which carbon dioxide was essential to both diagnosis and therapeutic decision-making in a type IA endoleak.
\end{abstract}

Keywords: endoleak; endovascular procedure; aneurism; carbon dioxide; angiography.

\section{Resumo}

O tratamento endovascular dos aneurismas de aorta abdominal é atualmente a modalidade de tratamento mais comum. Os endoleaks representam a causa mais frequente de reintervenção após o tratamento endovascular. $\mathrm{O}$ diagnóstico do tipo de endoleak frequentemente é incerto, tornando o tratamento desafiador. Apresentamos o caso de um paciente de 72 anos, com endoleak após 2 anos de tratamento endovascular de aneurisma de aorta abdominal. Os exames de imagem pré-operatórios sugeriam um endoleak tipo III; entretanto, durante aortografia com contraste iodado, não foi possível identificá-lo. Optamos por realizar aortografia com dióxido de carbono $\left(\mathrm{CO}_{2}\right)$, sendo, então, identificado um endoleak tipo IA, que foi tratado com sucesso com o uso de uma extensão (cuff) proximal. O papel do $\mathrm{CO}_{2}$ no diagnóstico de endoleaks ainda não está claro. Relatamos um caso em que o uso do $\mathrm{CO}_{2}$ foi essencial para o diagnóstico e para a decisão de tratamento do endoleak tipo IA.

Palavras-chave: endoleak; procedimento endovascular; aneurisma; dióxido de carbono; angiografia.

How to cite: Megale AB, Mendes CA, Teivelis MP, Faustino CB, Souza KP, Wolosker N. Use of carbon dioxide for therapeutic decision-making in endoleaks: a case report. J Vasc Bras. 2020;19:e20200060. https://doi.org/10.1590/1677-5449.200060 


\section{INTRODUCTION}

Endovascular repair (EVAR) is now the most frequent treatment modality for infrarenal aortic aneurysms. ${ }^{1}$ It is associated with lower 30-day mortality rates compared to open repair. ${ }^{2}$ EVAR is also correlated with a higher reintervention rate, which can be as high as $20 \%$ in the first 5 years. ${ }^{3}$

Endoleaks constitute the main cause of reinterventions. ${ }^{4}$ It is often unclear which type of endoleak is the correct diagnose,${ }^{5}$ making the treatment decision difficult.

Diagnostic aortography is generally performed with iodinated contrast. However, even with power injectors and high doses of iodinated contrast, there is occasionally still doubt with regard to which type of endoleak is present. In this situation, carbon dioxide $\left(\mathrm{CO}_{2}\right)$ represents an alternative method that can solve the problem. ${ }^{6}$

We conducted a literature review and were unable to find any papers reporting use of $\mathrm{CO}_{2}$ as being crucial for the decision on how to treat an endoleak. ${ }^{7}$

We report a case in which an endoleak identified after EVAR was defined as type III by computed tomography angiography (CTA) and contrast-enhanced ultrasound (CEU). However, during the intervention, iodinated contrast aortography did not show presence of any endoleaks, but when aortography with $\mathrm{CO}_{2}$ was used, a type IA endoleak was evident. This was successfully treated with placement of a proximal cuff in the aorta.

\section{CASE REPORT}

We describe the case of a 72-year-old male patient with a past medical history of hypertension and atrial fibrillation treated by anticoagulation with warfarin. He originally presented with an infrarenal aortic aneurysm with a maximum diameter of $6.5 \mathrm{~cm}$ and a concomitant left common iliac artery aneurysm of $4.9 \mathrm{~cm}$.

The patient was successfully treated by EVAR with Incraft ${ }^{\circledR}$ main body - 30mm x $98 \mathrm{~mm}$; ipsilateral branch $-13 \mathrm{~mm} \times 140 \mathrm{~mm}$; and contralateral branch - 24mm x 100mm (Cordis, Cardinal Health, Dublin, $\mathrm{OH}, \mathrm{EUA}$ ) and embolization of the left internal iliac artery with coils, two years ago.

In accordance with our institutional protocol, the patient underwent CTA 30 days postoperatively, showing a type II endoleak connecting the left iliac artery aneurysm (embolized), inferior mesenteric artery, and two lumbar arteries, with expansion of the aneurysm sac to $7 \mathrm{~cm}$.

Since the patient was under anticoagulation, we first attempted cessation of warfarin for 3 months and clinical follow-up. After that period, CTA showed the same endoleak, but with stability of the aneurysm diameter and less contrast flow in the sac.

After 6 months, a repeat CTA demonstrated stability of the aneurysm diameter.

At the 1-year control CTA, a $7.1 \mathrm{~cm}$ diameter sac was observed with no remaining type II endoleaks. However, a new contrast area was seen on the anterior surface of the stent graft, which was suspected to be a type III endoleak (Figure 1).

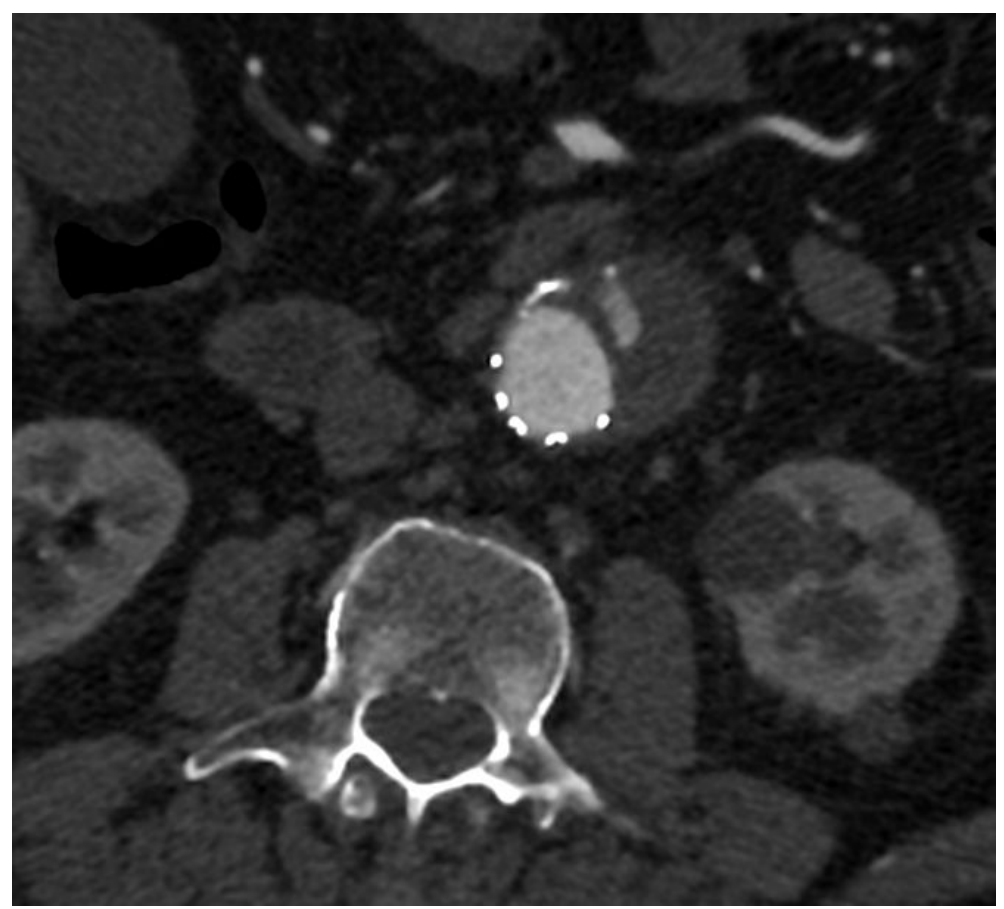

Figure 1. CTA 1 year after the EVAR showing leaking contrast at the anterior face of the main endograft body. 


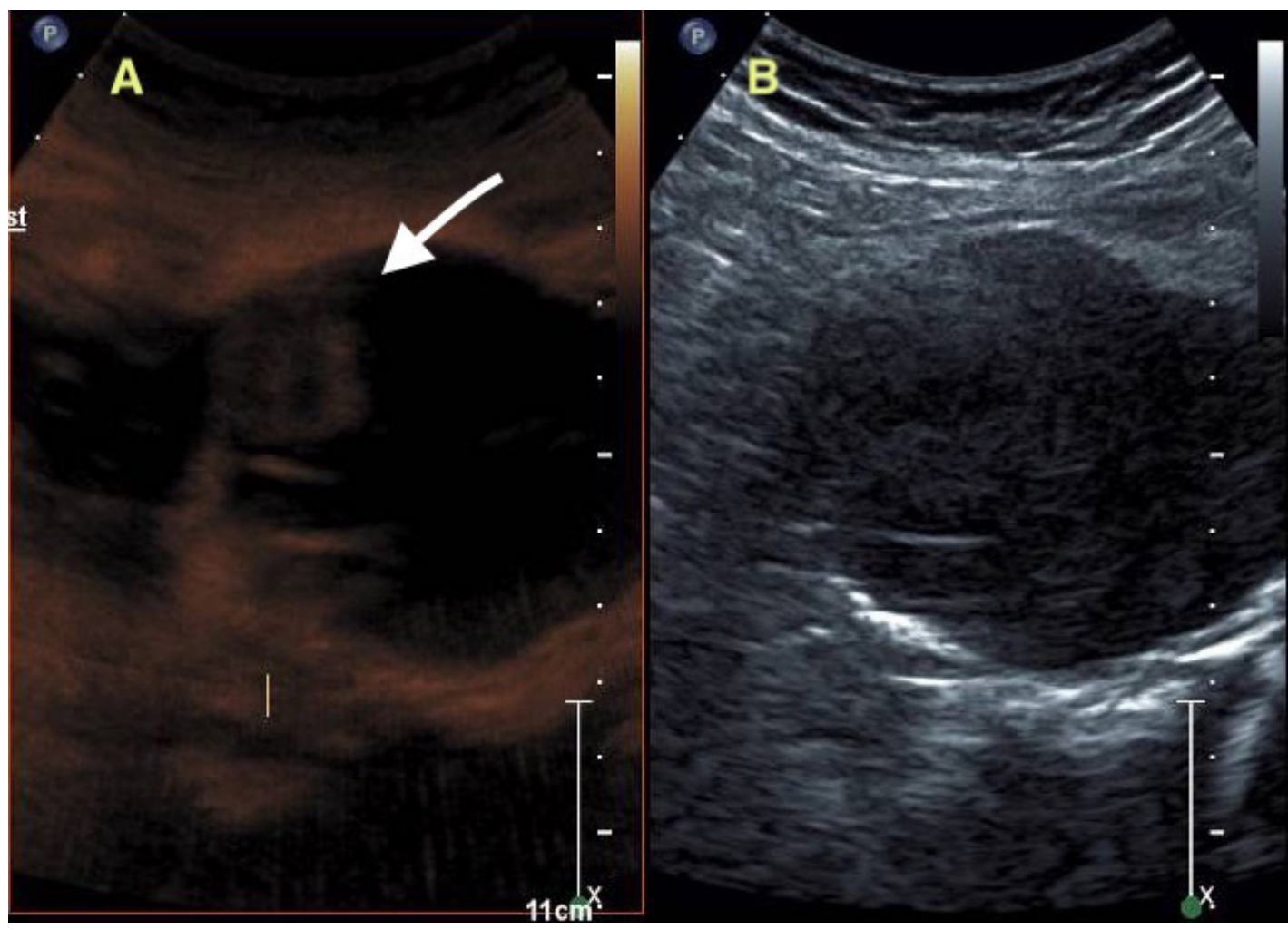

Figure 2. (A) CEU showing endoleak in the anterior face of the endograft; (B) B-mode image of the endograft.

During further investigation, CEU showed a high-flow endoleak on the anterior surface and a possible stent fracture. Also, a low-flow endoleak of the anterior lumbar and the left internal iliac arteries were observed with CEU (Figure 2).

At this point the decision was taken to proceed with endovascular treatment, due to the small change in the aneurysm sac and the suspicion of an endograft fracture.

During the intervention, aortography was performed with iodinated contrast and a power injector in 30-degree left oblique and 90-degree left oblique incidence angles, and no endoleaks were identified (Figure 3).

Different positions were assessed with the pigtail catheter: next to the suprarenal fixation, to the main body of the endograft, and inside the iliac branches. No contrast flow was seen in the aneurysm sac.

We further performed aortography with $\mathrm{CO}_{2}$. The first injection was made manually with a pigtail catheter and $30 \mathrm{ml}$ of $\mathrm{CO}_{2}$ in a $60 \mathrm{ml}$ syringe with a 90 -degree left oblique incidence angle, but no endoleaks were observed.

Finally, we used a Simmons 1 catheter with the same incidence and volume, identifying an endoleak at the anterior surface, originating from the proximal

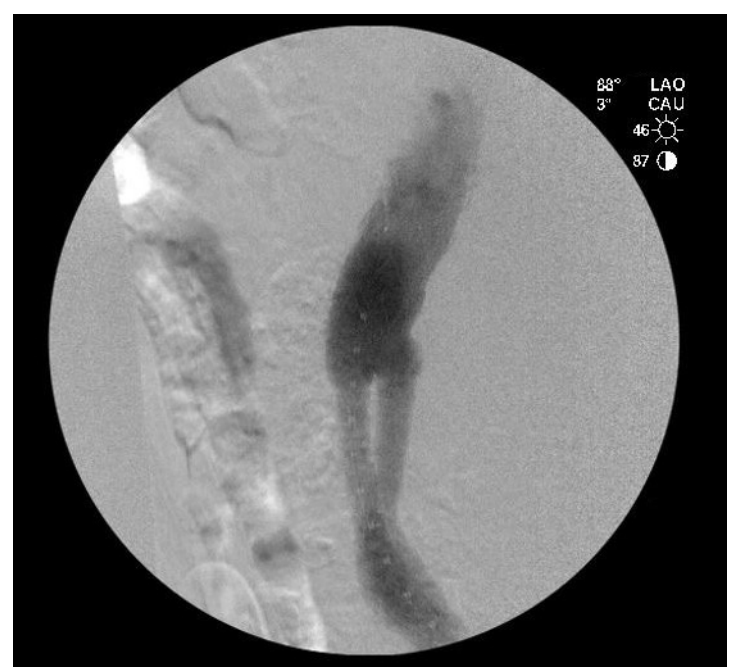

Figure 3. Aortography with iodinated contrast and power injector with no visible endoleak.

portion of the endograft, which we characterized as a type IA endoleak (Figure 4).

No signs of fracture or contrast leakage from the stent graft could be seen.

After this diagnosis, the patient was successfully treated with a proximal cuff(Incraft ${ }^{\circledR} 34 \mathrm{~mm}$ x $42 \mathrm{~mm}$ ). Control aortography with $\mathrm{CO}_{2}$ showed no endoleaks. 


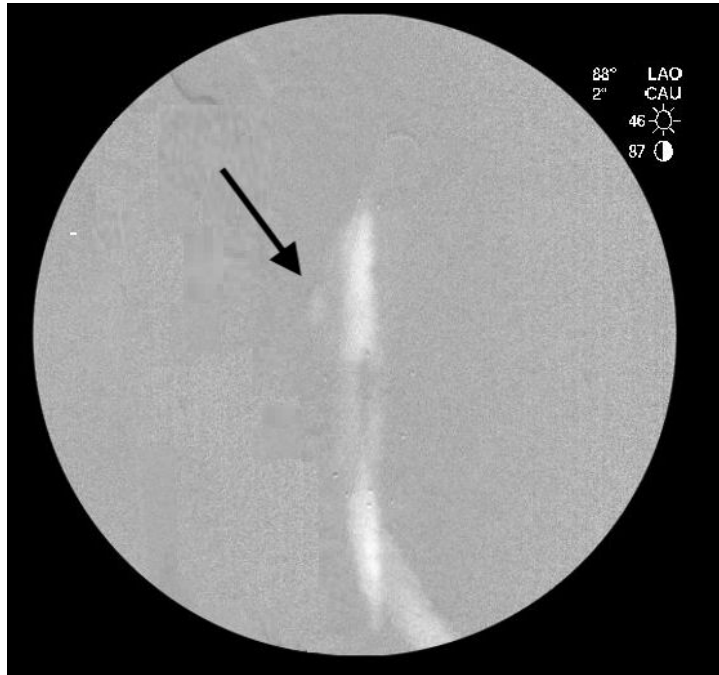

Figure 4. Aortography with $\mathrm{CO}_{2}$ and Simmons 1 catheter. An endoleak was identified in the free-flow area (black arrow), arising from the proximal part of the main body.

Thirty days after the intervention, another CTA was performed, showing no contrast in the aneurysm sac.

\section{DISCUSSION}

Endoleaks are the main cause of reintervention after EVAR. When type I endoleaks are identified at the time of the final aortography after EVAR, they are usually considered to justify treatment. ${ }^{4}$ Type II endoleaks are mostly benign. However, in a few cases, they can cause enlargement of the sac and can eventually lead to rupture. ${ }^{8}$ Type III endoleaks are associated with a higher risk of rupture and aneurysm sac enlargement and should always be treated. ${ }^{9}$

Conflicting diagnostic results regarding the type of endoleak are frequent. In a 2019 study by Madigan et al. with 130 patients with type II endoleaks, $22 \%$ of the patients who needed treatment had a type I or III endoleak that had been previously misidentified and were only correctly diagnosed during the intervention. ${ }^{9}$

In the case reported here, the patient was followedup in order to investigate the type II endoleak and, due to sac enlargement and suspicion of a stent graft fracture, a treatment decision was necessary.

During the preoperative investigation, a type III endoleak had been considered, but it was only during the endovascular procedure, after $\mathrm{CO}_{2}$ injection, that a type I endoleak was identified.

It is important to remember that both CTA and CEU results suggested a type III endoleak, and only $\mathrm{CO}_{2}$ aortography was capable of demonstrating that the endoleak was actually from the proximal landing zone of the endograft (type IA).
It is no novelty that $\mathrm{CO}_{2}$ can be used as an alternative contrast for EVAR. In 2011, Criado et al. performed 114 EVAR procedures with $\mathrm{CO}_{2}$ and observed 20 endoleaks (two type I, sixteen type II, and two type IV). No additional endoleaks were diagnosed with iodinated contrast. No type I or III endoleaks were identified with CTA after the first month of follow-up. ${ }^{10}$

The comparison between $\mathrm{CO}_{2}$ and iodinated contrast for detecting endoleaks is still under debate.

In 2018, Mascoli et al. compared the accuracy of $\mathrm{CO}_{2}$ with iodinated contrast and $\mathrm{CEU}$ in 21 patients. All type I and III endoleaks were detected with iodinated contrast and $\mathrm{CO}_{2}$. Seven type II endoleaks were identified with $\mathrm{CO}_{2}$; of these, only one was diagnosed with iodinated contrast and four with CEU; therefore, two of them were only recognized using carbon dioxide. ${ }^{5}$

In 2015, Sueyoshi et al. observed that all type I and type III endoleaks were identified by both methods (iodinated contrast and $\mathrm{CO}_{2}$ ), but $\mathrm{CO}_{2}$ was less sensitive than iodinated contrast for detecting type II endoleaks. ${ }^{2}$

An automated $\mathrm{CO}_{2}$ injection method for EVAR was presented by Mascoli et al. in 2018. In this study with 31 patients, it was possible to identify all type I and III endoleaks using the automated method. However, they reported that $\mathrm{CO}_{2}$ had higher sensitivity for type II endoleaks than iodinated contrast. ${ }^{11}$

Even though $\mathrm{CO}_{2}$ was manually injected in this case report, it was only when the gas was used that it was possible to detect the type I endoleak.

One technical point was that the image was only conclusive after injection with an end-hole catheter in the same direction as the blood flow. This technique has been previously described for performing EVAR by Criado et al., in 2011, and by Mendes et al. in 2016.,10

In 2011, Criado et al. used an end-hole catheter to conduct final angiograms after EVAR. ${ }^{10}$ In 2018, Mascoli et al. injected $\mathrm{CO}_{2}$ from the sheath, with the patient in the Trendelenburg position. ${ }^{6}$ This could have enhanced the good sensitivity they achieved with $\mathrm{CO}_{2}$ for identifying endoleaks. Sueyoshi et al. did not provide enough information about the method of $\mathrm{CO}_{2}$ injection used. ${ }^{5}$

When $\mathrm{CO}_{2}$ is used with a pigtail catheter, its low viscosity leads to explosive effect, producing bubbles and resulting in lower quality images. It provides higher quality images when injected with an endhole catheter.

The patient described in this study was admitted to the operating room with a suspected type III endoleak diagnosed by CEU and CTA. Injection of iodinated contrast excluded this diagnosis, but did not show 
the location of the endoleak that had been shown in previous images.

Use of $\mathrm{CO}_{2}$ permitted detection of the type IA endoleak. This was probably because it was a small endoleak, hence the slow enlargement of the aneurysm sac. Once the endoleak had been diagnosed, it was possible to treat it using a proximal cuff to repair the problem.

\section{CONCLUSION}

Treatment of endoleaks after EVAR represents a challenge. It is important to use multiple diagnostic and therapeutic methods for proper management.

Angiography with $\mathrm{CO}_{2}$ constitutes a supplementary method to conventional angiography with iodinated contrast. However, further studies to establish the real accuracy of this method would be welcomed.

\section{REFERENCES}

1. de Almeida Mendes C, de Arruda Martins A, Teivelis MP, Kuzniec S, Varella AYM, Wolosker N. Carbon dioxide as contrast medium to guide endovascular aortic aneurysm repair. Ann Vasc Surg. 2017;39:67-73. http://dx.doi.org/10.1016/j.avsg.2016.06.028. PMid:27671460.

2. Budtz-Lilly J, Wanhainen A, Mani K. Outcomes of endovascular aortic repair in the modern era. J Cardiovasc Surg (Torino). 2018;59(2):180-9. PMid:29206004.

3. Patel SR, Allen C, Grima MJ, et al. A systematic review of predictors of reintervention after evar: guidance for risk-stratified surveillance. Vasc Endovascular Surg. 2017;51(6):417-28. http:// dx.doi.org/10.1177/1538574417712648. PMid:28656809.

4. AbuRahma AF, Hass SM, AbuRahma ZT, et al. Management of immediate post-endovascular aortic aneurysm repair type ia endoleaks and late outcomes. J Am Coll Surg. 2017;224(4):740-8. http://dx.doi.org/10.1016/j.jamcollsurg.2016.12.014. PMid:28017805.

5. Sueyoshi E, Nagayama H, Sakamoto I, Uetani M. Carbon dioxide digital subtraction angiography as an option for detection of endoleaks in endovascular abdominal aortic aneurysm repair procedure. J Vasc Surg. 2015;61(2):298-303. http://dx.doi. org/10.1016/j.jvs.2014.07.088. PMid:25151598.

6. Mascoli C, Faggioli G, Gallitto E, et al. The assessment of carbon dioxide automated angiography in type ii endoleaks detection: comparison with contrast-enhanced ultrasound. Contrast Media Mol Imaging 2018;2018:7647165.http://dx.doi.org/10.1155/2018/7647165.PMid:29780288.

7. Garvin RP, Ryer EJ, KendrickJB, Franklin DP. Endoleak visualized with carbon dioxide angiography during endovascular aneurysm repair using the endurant stent-graft. J Endovasc Ther. 2014;21(1):172-6. http://dx.doi.org/10.1583/12-4123MR.1. PMid:24502499.

8. Wolosker N, Varella AY, Teivelis MP, Mendes CA, Garcia RG, Pfeferman E. Successful image-guided percutaneous embolization of a ruptured abdominal aortic aneurysm sac due to type II endoleak after endovascular repair. Ann Vasc Surg. 2015;29(2):361.e1-4. http://dx.doi.org/10.1016/j.avsg.2014.10.016. PMID: 25463347.

9. Madigan MC, Singh MJ, Chaer RA, Al-Khoury GE, Makaroun MS. Occult type I or III endoleaks are a common cause of failure of type II endoleak treatment after endovascular aortic repair. J Vasc Surg. 2019;69(2):432-9. http://dx.doi.org/10.1016/j.jvs.2018.04.054. PMid:30686338.

10. Criado E, Upchurch GR Jr, Young K, et al. Endovascular aortic aneurysm repair with carbon dioxide guided angiography in patients with renal insufficiency. J Vasc Surg. 2011;54(5):1544-5. http://dx.doi.org/10.1016/j.jvs.2011.09.030. PMid:22341837.

11. Mascoli C, Faggioli G, Gallitto E, et al. Standardization of a carbon dioxide automated system for endovascular aortic aneurysm repair. Ann Vasc Surg. 2018;51:160-9. http://dx.doi.org/10.1016/j. avsg.2018.01.099. PMid:29522871.

Correspondence
Adalberto Megale
Hospital Israelita Albert Einstein
Av. Albert Einstein 627, Bloco A1, 40 andar, sala 423, Morumbi
CEP 05652-000 - São Paulo (SP), Brasil
Tel.: +55 (11) 2151-5423
E-mail: adalbertomegale@hotmail.com

Author information $A B M$ and KPS - MD, Vascular surgery residents, Hospital Israelita Albert Einstein (HIAE). CAM and CBF - MD, PhD, Vascular surgery assistant, Hospital Israelita Albert Einstein (HIAE).

MPT - MD, PhD, Vascular surgery assistant, Hospital Israelita Albert Einstein (HIAE); Assistant professor, Faculdade de Medicina, Faculdade Israelita de Ciências da Saúde Albert Einstein. NW - MD, PhD, Vice president, Hospital Israelita Albert Einstein (HIAE); Vascular surgery assistant, HIAE.

Author contributions Conception and design: ABM, CAM, MPT, CBF, KPS Analysis and interpretation: $A B M, C A M, M P T, C B F, K P S$ Data collection: ABM, CAM, MPT, CBF, KPS Writing the article: ABM, CAM, MPT, CBF, KPS Critical revision of the article: MPT, CAM, NW Final approval of the article*: ABM, CAM, MPT, CBF, KPS, NW Statistical analysis: N/A Overall responsibility: ABM, CAM, NW

*All authors have read and approved of the final version of the article submitted to J Vasc Bras. 